\title{
DO EXOGENOUS SHOCKS HELP OR HURT INNOVATION PERFORMANCE OF ALLIANCES? EVIDENCE FROM EBOLA OUTBREAK
}

\author{
BIRGUL ARSLAN \\ College of Administrative Sciences and Economics \\ Koç University \\ Rumelifeneri yolu, No:1 34450 Istanbul \\ MURAT TARAKCI \\ Erasmus University, Rotterdam School of Business
}

\begin{abstract}
Building on attention-based view, we argue that exogenous shocks affect alliance performance by steering managerial attention. We find that while the innovation performance of Ebola alliances formed after the 2014 outbreak increased, performance of Influenza alliances decreased. Our study reveals negative spillover effects of industry shocks among related industry segments.
\end{abstract}

\section{INTRODUCTION}

Organizations forge alliances to address innovation challenges in response to exogenous shocks (Asgari, Singh, \& Mitchell, 2017; Schilling, 2005; Tao, Jiang, \& Santoro, 2015). The underlying advantage is that alliances enable access to complementary capabilities and resources (Asgari et al., 2017; Dyer \& Singh, 1998; Stuart, 2000) in ways that foster knowledge flows among partners (Gomes-Casseres, Hagedoorn, \& Jaffe, 2006; Mowery, Oxley, \& Silverman, 1996). True to form, alliances have yielded more patents (Ahuja, 2000; Shan, Walker, \& Kogut, 1994; Stuart, 2000) and new products (Deeds \& Hill, 1996; Hagedoorn, Lokshin, \& Zobel, 2018; Rothaermel \& Deeds, 2004). Nevertheless, the literature also documents broad dissatisfaction with alliance outcomes and high rates of alliance failure (Geringer \& Hebert, 1989; Makino, Chan, Isobe, \& Beamísh, 2007; Park \& Ungson, 2001). Alliance formation in response to shocks may just stem from organizations mirroring each other in fear of being locked out of potential partnerships (Gomes-Casseres, 1994) or due to legitimacy pressures (DiMaggio \& Powell, 1983) rather than out of sound performance expectations (Garcia-Pont \& Nohria, 2002). Consequently, the benefits of alliances remain unclear when forged in response to a sudden exogenous shock mobilizing an industry (e.g., viral outbreaks, breakthrough technologies or regulatory changes). Understanding how exogenous industry shocks affect alliance innovation performance is essential not only to guide business practices leveraging alliances, but also to offer insights into the contextual and temporal aspects of interorganizational collaborations (Lumineau \& Oliveira, 2017; Oliveira \& Lumineau, 2018).

We have developed an attention-based view of interorganizational collaborations that hypothesizes that exogenous shocks foster alliance innovation performance only in the industry segment directly affected by the shock while hurting the performance of alliances formed in related industry segments not directly experiencing the shock. This is because the urgency and upside opportunity created by the shock draw the necessary managerial attention to alliance activities. Conversely, alliance performance in the related industry segments suffers from 
lowered managerial attention. Attention, in turn, affects resource deployment and interest alignment among alliance partners. We find support for our hypotheses in the context of drug development alliances formed by biotechnology and pharmaceutical firms during the eight years framing the 2014 Ebola outbreak.

Our study contributes in three important areas. First, prior research has rarely focused on the external context and timing in which collaborative relationships transpire (for reviews, see Lumineau \& Oliveira, 2017; Oliveira \& Lumineau, 2018). It also remains unclear whether alliances formed in response to exogenous shocks achieve the desired alliance-level outcomes. Second, our study, to the best of our knowledge, is the first to examine interdependencies among alliances formed in different industry segments. Third, we extend the attention-based view's (Ocasio, 1997, 2011) firm-level focus to the alliance-level to uncover the performance consequences of managerial attention allocation within the context of interorganizational collaborations.

\section{THEORY AND HYPOTHESES}

Forming interorganizational collaborations, i.e., strategic alliances, has been a leading response to shocks (Asgari et al., 2017; Schilling, 2015). This is because strategic alliances foster knowledge flows among partners (Gomes-Casseres et al., 2006; Mowery et al., 1996) that help make sense of and gain insights into the emerging technologies (Hoffmann, 2007; Mitchell \& Singh, 1992). Here, alliance partners can pool their capabilities and resources (Powell, White, Koput, \& Owen-Smith, 2005; Rothaermel, 2001). Joining forces with other organizations enables alliance partners to tackle innovation challenges more easily than on their own when innovations require considerable resources, knowledge, and speed. These studies have unearthed valuable insights into firm-level benefits of alliances. However, existing research has seldom considered the alliance-level effects of industry shocks. This is a key limitation in our understanding of when and how alliances deliver the intended benefits in the face of industry shocks. Although alliances are expected to provide access to partner resources and expedite innovations, they do not assure resource deployment in the face of coordination costs and misappropriation concerns (Gulati \& Singh, 1998; Khanna, Gulati, \& Nohria, 1998).

Coordination hardships often impart friction to the process of creating synergies among alliance partners. Concerns about misappropriation result in defensive and tightened control in the alliance, thus curbing the joint value-creation potential (Katila, Rosenberger, \& Eisenhardt, 2008; Luo, 2007). Given that such inter-partner dynamics pose a grave test in the way of achieving alliance aims, it is vital to understand when and how external dynamics ease or complicate alliance management.

Organizations are limited in their capacity to process and address environmental stimuli (Simon, 1947). Organizations thus attend to the issues in their environments selectively (Ocasio, 1997, 2011). Among the plethora of issues competing for attention, those with greater urgency, legitimacy, value, and organizational relevance attract higher levels of organizational attention. Sudden industry shocks trigger substantial press and analyst coverage calling for an appropriate action plan, thereby establishing legitimacy of action. They also prompt new opportunities (Schilling, 2015) and experimentation with a variety of technologies (Argyres, Bigelow, \& Nickerson, 2015; Kaplan \& Tripsas, 2008; Tushman \& Anderson, 1986) in a race for first-mover advantages. Owing to their urgency and upside potential, exogenous industry shocks are likely to attract significant attention from organizations. 
Such attention directed toward an industry shock, in turn, affects alliance performance (i) by channeling organizational resources and (ii) by aligning the incentives of alliance partners around shared goals. First, alliances formed after an industry shock are endowed with more resources to fuel the innovation activities in the domain affected in comparison to those formed before the shock. The more mindful organizations are to an issue, the more resources are steered in that direction (Baumann, Eggers, \& Stieglitz, 2018; Ocasio \& Joseph, 2008; Tarakci, Ates, Floyd, Ahn, \& Wooldridge, 2018). Resources allocated to an alliance activity are critical for innovation outcomes (for a review, see Acar, Tarakci, \& van Knippenberg, 2019). Alliances in an industry segment experiencing a shock, therefore, receive more managerial attention and benefit from added resource deployment favoring alliance innovation outcomes.

Partner incentive alignment is another reason why alliances formed after an exogenous shock attain higher innovation performance than those formed earlier. When partner interests modestly overlap, each partner pursues its own interests at the expense of joint value creation (Park \& Ungson, 2001). Significant prospects of common benefits can align incentives among alliance partners while curbing internal competitive behavior toward private benefit extraction (Arslan, 2018). Exogenous shocks create this perception of high common benefits by opening up a new pool of revenue, conveying to successful firms a potentially durable, first-mover advantage and market leadership after a fierce industry shakeout (Argyres et al., 2015). Alliances formed in response to an industry shock, therefore, are more likely to align partnership interests toward achieving the alliance objectives versus reaping private benefits. Therefore, we expect:

\section{Hypothesis 1: Alliances formed after an exogenous industry shock in a focal industry segment achieve higher innovation performance than the alliances formed before the shock in that industry segment.}

As new events develop in the external environment, organizational attention reallocates to the newly salient issues from previously important issues and priorities. Managers become less likely to allocate their time, effort and resources to issues failing to garner their attention (Gaba \& Joseph, 2013; Rhee, Ocasio, \& Zajac, 2018). Thus, alliances formed in a related industry area after a shock drive less managerial attention and resources than those formed earlier.

Furthermore, the relative lack of resources hampers partner cooperation and the commitment to achieving common benefits. This, in turn, exacerbates friction in the alliance and worsen incentive misalignment. Partners become more likely to focus on private benefit extraction at the expense of realized common benefits. Accordingly, we expect:

\section{Hypothesis 2: Alliances formed after an exogenous industry shock in a related industry segment achieve lower innovation performance than those formed before the shock in that related industry segment.}

\section{EMPIRICAL SETTING AND RESULTS}

The 2014 Ebola outbreak is our empirical context. In March 2014, World Health Organization (WHO) officially announced an outbreak of Ebola Virus Disease in West Africa. At the time, there were no treatment options beyond supportive care. In less than a year, the virus infected 21,206 people and claimed 8,386 lives. The prevalence and the complexity of the outbreak attracted significant public attention. In 2014 alone, 54,310 media pieces appeared, 
representing a nearly 130 -fold increase in news coverage. Fueled by the increased media attention, the outbreak sparked an innovation race among industry players and a surge of alliances in the fight against the Ebola virus. We identified Influenza as the industry segment affected by the Ebola outbreak because the Influenza virus most closely mimics Ebola's genome structure. Both Influenza and Ebola viruses have a negative-sense, single-stranded RNA with no DNA step in replication, thus corresponding to the same virus group in Baltimore Classification System.

We observed drug development alliances formed between 2010 and 2017 covering \pm 4 years around the outbreak. We included alliances where at least one of the partners was a firm. We limited the sample to drug development alliances so as to exclude co-development of diagnostic tests and technology platforms.

We measured alliance innovation performance as the progression of the drug candidate to the next phase in the drug development process. This process comprises the following sequential stages of development: (i) discovery, (ii) phase 1 clinical, (iii) phase 2 clinical, (iv) phase 3 clinical, (v) pre-registration, (vi) registered, (vii) and launched. The variable alliance progress was coded 1 for drugs proceeding further in the development process relative to its starting status, coded 0 for no development reported, and coded -1 for drugs suspended, withdrawn or discontinued after the alliance formation. To estimate the effect of the Ebola outbreak on the innovation performance of the newly formed alliances, we constructed the variable outbreak-a dichotomous variable coded 1 for alliances formed after the official WHO announcement of the outbreak in 2014. We coded the alliances formed before the outbreak as 0 . We included several control variables addressing the drug, alliance and partner relationship characteristics.

We used the competing risks regression to test our hypotheses, which assumes that alliances are 'at risk' to proceed to the next development phase or to being suspended during the observation period. This strategy takes into account the right-censoring issue of observing alliances until a specific point in time.

Findings indicate that Ebola alliances formed after the outbreak were significantly more likely to progress to the next stage compared to the alliances formed in the period before the outbreak, lending empirical support to Hypothesis 1. On the contrary, the outbreak was associated with a significant reduction in the likelihood of progress in post-outbreak Influenza alliances compared to those formed in the period before the outbreak, supporting Hypothesis 2 . We also found that the positive performance impact of the Ebola outbreak on Ebola alliances diminished over time. Ebola alliances formed shortly after the outbreak were more likely to progress than alliances formed later whereas the effect reversed for Influenza alliances. Accordingly, the negative performance impact of the Ebola outbreak on Influenza alliances faded over time, showing that Influenza alliances formed shortly after the Ebola outbreak were most negatively affected. These findings lend some support for shifts in managerial attention underlying the observed performance levels in Ebola and Influenza alliances.

\section{DISCUSSION}

This study set out to understand the impact of industry shocks on strategic alliance performance with a focus on possible interdependencies among the industry segments both directly and indirectly affected by the innovation race. The main argument we developed draws from the attention-based view: while salient industry events lead to channeling attention to the most affected segment, they also trigger withdrawals of attention from other related segments. 
This reallocation of attention - and its cascade of time, effort and resources - raises performance in the affected segment while harming related-segment results.

We have hypothesized and provided empirical evidence that shocks improve alliances' innovation performance in industry segments experiencing the shock at the expense of the performance in the related segments not directly facing that shock. Equally interesting, the shock effect was fleeting, likely driven by the temporary spike in attention toward the shock. Our study offers new insights into alliance outcomes by invoking the larger context in which alliances transpire along with its cognitive and behavioral impacts on alliance performance.

Our findings also have important managerial implications. They highlight the importance of effective attention regulation during exogenous shocks to its industry. Managers can lift alliance performance in industry segments stirred to an innovation race by capitalizing on increased commitment and incentive alignment with their partners. On the other hand, they may safeguard alliances in related industry segments against deteriorating motivation and commitment in order to exploit previously expanded resources and productive relationships.

REFERENCES AVAILABLE FROM THE AUTHORS 